\title{
Violencia Lingüística en las Redes Sociales
}

\author{
Susana CAmpillo MuÑOZ* \\ Universitat Rovira i Virgili, Tarragona, Spain
}

\begin{abstract}
Taking into account that, currently, violence is a very frequent phenomenon, this article analyzes a specific type of violence, namely linguistic violence. Specifically, out analysis deals with two topics: the different degrees of violence in speech acts and the resources and techniques that are used to produce violent utterances. By considering politeness studies focused on impoliteness, the work proposes a categorization of violent speech acts that reflects different levels of violence, understanding, therefore, violence as a gradual and noncategorical concept. In the study, a corpus of interactions extracted from Twitter and Facebook is analyzed. The rise of social networks, their ease of use and their features make of these platforms an excellent database for this type of analysis. The results show a significant presence of high levels of linguistic violence in social networks, being the implicitness a feature that in most cases characterizes these utterances. Those results led to reconsider the common idea that defends that explicitness is necessary in order to label an action as violent, and the outstanding presence of high violence categories. It would be necessary to pay more attention to the violent implicit content of utterances which, as shown by the analysis, is not less violent than the explicit one.
\end{abstract}

Keywords: Violence, language, impoliteness, social networks.

Resumen. Considerando que la violencia es un fenómeno muy presente en la actualidad, en el presente artículo se expone el estudio cuyo objetivo es analizar un tipo de violencia especí-

\footnotetext{
* Author's address:

Departament de Filologies Romàniques

Universitat Rovira i Virgili

Av. Catalunya 35, 43002 Tarragona, Spain

E-mail susana.campillo@urv.cat
} 
fico: la violencia lingüística. En concreto, se ocupa de los grados de violencia, así como de los recursos y las técnicas que se utilizan para emitir actos de habla violentos. Con un análisis de los estudios cartesiológicos, centrado en la descortesía, se ofrece una propuesta de categorías de violencia y diferentes grados. En el estudio realizado se analiza un corpus de ejemplos extraído de las redes sociales Twitter y Facebook; el auge de estas plataformas, su facilidad de uso y sus características convierten a este tipo de plataformas en un excelente banco de datos para realizar estudios como el que se plantea en el trabajo desarrollado. Los resultados obtenidos tras el análisis del corpus muestran la importante presencia de grados altos de violencia lingüística en las redes sociales y la implicitud, en la mayoría de los casos, que caracteriza a estos enunciados. Cabe, quizá, replantearse la necesaria explicitud de las acciones para que sean consideradas violentas, así como la destacada presencia de las categorías de alta violencia. Es necesario prestar más atención a las acciones implícitas que, como demuestra el análisis, no restan carácter violento al enunciado.

Palabras clave: Violencia, lenguaje, descortesía, redes sociales.

\section{Introducción}

En la actualidad, la violencia se halla en muchos aspectos cotidianos, tanto globales o colectivos como personales o individuales. En los últimos años, el número de acciones agresivas ha ascendido, como muestran los medios de comunicación que diariamente se hacen eco de noticias sobre casos de violencia.

Como acción del ser humano, la violencia puede llevarse a cabo mediante actos de habla que, generalmente, la sociedad percibe como menos violentos que las agresiones físicas. Creemos que, aunque la presencia de daño es necesaria para hablar de violencia, éste no ha de ser ni inmediato ni altamente perceptible. De hecho, la violencia lingüística, más sutil que la física, pasa por ser en muchos casos implícita.

La descortesía, tratada como violencia, ha sido investigada en el ámbito hispánico en las dos últimas décadas (Haverkate 2012; Brenes Peña 2007-2009; Blas Arroyo 2008-2010; Fuentes 2008-2009-2010; Programa EDICE, etc.). Sin embargo, su presencia en las redes sociales no ha recibido una atención especial.

Internet, la Web 2.0 y las redes sociales se han convertido en un gran corpus para el estudio de la comunicación, sobre todo para análisis que adopten un enfoque sociopragmático o sociolinguiístico, así como los usos sociales de las tecnologías (Androutsoupoulos y Beisswenger 2008).

Así, las redes sociales se han convertido, desde la década de los 90, en una fuente de corpus lingüístico para el estudio de la comunicación mediada por ordenador (Pano 
Alamán y Moya Muñoz 2016; Pano Alamán y Mancera Rueda 2014b). Además, conforman un contexto en el que "han surgido conductas hasta ahora inéditas" (Gómez Arraigada 2013). Éstas permiten el mayor grado de interactividad en la red (Ciber Sociedad 2009): los usuarios pueden comentar publicaciones ajenas con libertad y sin ninguna restricción: en Twitter el hashtag permite comentar la intervención de cualquier usuario, y en Facebook, el hecho de seguir un grupo o página permite a los internautas comentar otras publicaciones en esa página, aunque el usuario emisor "no se tenga en amigos $^{2}$ ".La inmediatez, ubicuidad y espontaneidad llevan al usuario a una revisión casi constante de estas aplicaciones, lo que propicia un incremento de uso.

El estudio que presentamos pretende analizar la violencia lingüística, estableciendo distintos grados y tipos de violencia; analizando las diferentes maneras de manifestarse la violencia en el lenguaje; y describiendo las estrategias utilizadas para enmascarar mensajes inherentemente violentos.

Para ello, nuestro trabajo se ha dividido en dos partes complementarias: una parte teórica, en la que se ha analizado la bibliografía sobre violencia lingüística y las teorías pragmáticas que sustentan nuestro análisis; y una parte empírica, en la que hemos recogido y analizado un corpus de datos propio procedente de las redes sociales.

Las redes sociales seleccionadas han sido Twitter y Facebook. La recopilación del corpus de ejemplos se ha realizado mediante las aplicaciones Storify y Twitter Archiver $^{3}$, y se han recogido 1270 publicaciones $^{4}$ (710 de Twitter y 560 de Facebook). El valor del corpus es cualitativo, no cuantitativo: se han seleccionado los comentarios que se han considerado significativos.

A su vez, se ha analizado la literatura sobre violencia lingüística y se ha propuesto una clasificación propia que, seguidamente, se ha aplicado en el análisis del corpus. No se trata de una clasificación genérica, otras clasificaciones serán igual de válidas.

${ }^{2}$ Twitter y Facebook son las redes sociales más populares: Facebook, $81 \%$; Twitter, 43\%, según el estudio del VII Observatorio Redes Sociales (16/12/2015).

${ }^{3}$ Storify permite seleccionar tuits y comentarios concretos, ordenarlos y descargar el documento que se ha creado; Twitter Archiver posibilita la recogida de tuits y retuits de un hashtag de manera masiva.

${ }^{4}$ Los anexos recogen el corpus de datos analizado. 


\section{Marco Teórico}

\subsection{Actos de Habla: Austin y Searle}

Austin en Cómo hacer cosas con palabras (1955) marca la discrepancia en relación con la definición tradicional de enunciado, cuya verdad depende de su correspondencia con la realidad objetiva. La base de la teoría que promulga es la distinción entre enunciados constatativos y realizativos: la misma oración puede ser empleada de manera realizativa o constatativa, han de adecuarse a los hechos o tener cierta relación con ellos. De entre otras teorías, ha estudiado el discurso indirecto como fenómeno social (Trenc 2014).

Seguidamente, sustituye esta dicotomía por tres fases o actos que conforman la emisión de un enunciado: el acto locucionario, el acto ilocucionario y el acto perlocucionario, que corresponden a la realización de acciones (el acto locucionario posee significado; el acto ilocucionario, fuerza, y el acto perlocucionario, efectos). Austin demuestra que hablar siempre es hacer algo y que un enunciado puede desempeñar diversas funciones, una de las cuales -no la única- es describir.

Searle (1986), discípulo de Austin, presta atención al significado del acto ilocucionario, fruto de la combinación de convención e intención. Así, la emisión de un enunciado en un contexto determinado es realizar convencionalmente una acción concreta (Ruiz Antón 1998). Searle (1976) defiende que es necesario distinguir entre dos fuerzas ilocucionarias: el acto primario, que no es literal, y el acto secundario, que es literal. Para distinguirlos, el interlocutor ha de ser consciente de que se trata de un enunciado indirecto y urge una estrategia inferencial, en la que entran en juego la información compartida (conocimiento léxico y enciclopédico) y la racionalidad (dentro de la cual está la memoria).

Aunque no existen reglas que determinen un acto de habla como indirecto, ciertas formas idiomáticas adquieren usos convencionales y son interpretadas como tal si el receptor posee las mismas claves culturales que el emisor (Searle 1976; Escandell Vidal 1993; Terkourafi 2008; Sperber y Wilson 1986).

\subsection{Cálculo del Mensaje Implícito: Teoría de la Relevancia}

Siguiendo el modelo inferencial, Sperber y Wilson (1986) defienden que el oyente ha de rellenar el enunciado con información extralingüística para, así, obtener una suposición enriquecida contextualmente que corresponde a una proposición (Portolés 2004). 
Con fuerte base en la teoría de Grice (1975), Sperber y Wilson toman la máxima de la relevancia como fundamental en la comunicación: siempre se cumple, pues los humanos actuamos según este principio (Albelda y Barros García 2013). Por ello, cualquier acto ostensivo (entre ellos, la comunicación verbal) conlleva la presunción de relevancia; se vincula con el efecto contextual: cuanto mayor es el efecto contextual, mayor es la relevancia.

El concepto de contexto es una representación del mundo compuesta por supuestos, conjuntos de conceptos estructurados de manera que su orden determina el modo en que han de procesarse. El contenido de un supuesto está determinado por las entradas lógicas de los conceptos que contiene, mientras que el contexto en el que se procesa está determinado por las entradas enciclopédicas de dichos conceptos. De este modo, la comunicación se basa en el deseo de alterar (maximizando o minimizando) el entorno cognitivo del interlocutor, de que sus procesos mentales se vean afectados, y el contexto se concibe como producto de la interpretación (Yus 1997).

Para llevar a cabo un procesamiento eficaz es necesario percibir la intención del emisor mediante la construcción de hipótesis, es decir, el reconocimiento de los supuestos a los que el emisor alude para garantizar que su estímulo es relevante.

Un mensaje verbal determina qué conceptos han de activarse y los reúne de forma lógica para que puedan ser usados como suposición (Yus 1997). Así, la comunicación comprende tres niveles:

1. La descripción lingüística (o entrada lógica)

2. Las representaciones semánticas (o entrada enciclopédica)

3. El esquema de supuestos (o derivaciones implicadas).

Para ello se requieren dos procesos pares: la codificación y descodificación, y la ostensión e inferencia.

Según la teoría de la relevancia, con la comprensión se obtiene inferencialmente una suposición enriquecida contextualmente que se corresponde con una proposición. Sperber y Wilson, pues, aportan una vía teórica que explica la comprensión en ausencia de muchos elementos contextuales físicos, puesto que el contexto surge de la combinación del mecanismo perceptivo con la memoria.

\subsection{Cortesía: Lo Socialmente Adecuado}

Las teorías cartesiológicas definen la cortesía como una decisión del hablante que depende del contexto: se trata de un mecanismo regulador de las relaciones sociales, 
no de la comunicación en sí, y el contexto es crucial para interpretarla (Haverkate 1994).

Desde una perspectiva cognitivista (como la de Sperber y Wilson), la cortesía es convención y tiene un papel importante en los supuestos previos que se tienen del comportamiento social adecuado (Albelda Marco y Barros García 2013): se toma la cortesía como lo esperado en determinado contexto. La cognición humana se sirve de dos módulos cognitivos especializados: el sistema cognitivo inferencial y el sistema cognitivo social; se lleva a cabo una doble actividad cognitiva (Yus 2010). La manifestación de cortesía, así, depende del contexto sociocultural (Bravo 2008; Brenes Peña 2009b)

La reiteración de comunicaciones forja una imagen cada vez más nítida de normas, intereses, metas comunes y demás que subyacen a la sociedad: crea simetría psicológica (Haverkate 2012).

\section{Teoría de la Cortesía}

Brown y Levinson (1987) postularon la teoría que más se ha empleado en los estudios pragmáticos y sociolingüísticos sobre cortesía, y tiene el propósito de complementar al estudio de Grice (1975) ocupándose de los aspectos sociales de la comunicación (Carrasco Santana 1999: 2).

Brown y Levinson definen la cortesía como la inferencia de los interlocutores acerca de las intenciones del hablante; por ello, la forma de los enunciados influye en cómo será interpretado por el receptor en términos de cortesía.

Los interactantes que toman como modelo son competentes miembros de una sociedad que poseen una imagen [traducción de face, tomado de Goffman (1967)], la propia imagen pública que todos los miembros quieren mantener. Esta imagen se divide en imagen positiva [o afiliación (Bravo 1999)] e imagen negativa [o autonomía (Bravo 1999) ] $]^{5}$.

Para Brown y Levinson la conversación es inherentemente conflictiva, pues amenaza a las imágenes de los interlocutores: algunos actos, como dar órdenes o prometer,

\footnotetext{
${ }^{5}$ Este modelo de cortesía aplicado al español será estudiado por Carrasco Santana (1999), Garrido Rodríguez (2006) y Haverkate (1994). Bravo (1999) incorpora el elemento sociocultural a la idea de imagen, de modo que la cortesía depende del grupo cultural, del contexto sociocultural en el que se realiza dicha actividad, así como de la modalidad discursiva y situacional del momento (Medina López 2011); la cortesía toma un valor relativo a la cultura.
} 
atacan la imagen negativa; otros, como criticar o insultar, la imagen positiva, aunque cabe la posibilidad de que se ataque a ambas imágenes en un mismo acto comunicativo.

Por ello, defienden el uso de determinadas estrategias lingüísticas que mitiguen estos actos amenazantes y proponen una fórmula para evaluar cuál es preferible, en la que se tienen en cuenta la distancia social, la relación de poder y el nivel de imposición permitido culturalmente $(\mathrm{W} x=\mathrm{D}(\mathrm{S}, \mathrm{H})+\mathrm{P}(\mathrm{H}, \mathrm{S})+\mathrm{R})$.

Con todo, destacan que no todos los hablantes escogerán la misma estrategia en las mismas condiciones, sino que es necesario sopesar cuándo las consecuencias serán menores y qué estrategia dará mejor resultado.

De este modo, dividen los actos amenazantes según si emplean estrategia y según si dicha estrategia es convencionalmente cortés o el enunciado es ambiguo:

- Actos directos [cumplimiento del Principio de Cooperacion de Grice (1975)].

- Actos con estrategia indirecta y abierta ${ }^{6}$ (adición de elementos para mostrar que no hay intención de dañar).

- Actos con estrategia encubierta (ambigüedad, se ofrece libertad de interpretación).

- Evitar el acto (desistimiento en la emisión del acto).

Brown y Levinson defienden que el uso del discurso indirecto es la estrategia que asegura la cortesía de cualquier acto, afirmación por la que han sido criticados (Terkourafi 2008; Carrasco Santana 1999; Haverkate 1994; Culpeper 1996). Se trata de la concepción tradicional de la cortesía como expresión de la distancia y estructura social, desde una perspectiva anglosajona.

\section{Teoría de la Descortesía}

Considerada, en oposición a la cortesía, como una agresión o amenaza intencional a la imagen del oyente (Albelda y Barros García 2013), la descortesía es un modo de comportamiento con fines estratégicos (Cepeda 2007).

Culpeper (1996) ofrece la contraparte del modelo de Brown y Levinson (1987), siguiendo firmemente los parámetros que establecen (Kaul de Marlangeon 2012). Así, enumera un conjunto de superestrategias, en oposición a las estrategias corteses:

${ }^{6}$ En este bloque distinguen entre cortesía positiva, si está orientada hacia la imagen positiva del oyente, y cortesía negativa, si está orientada hacia la imagen negativa del oyente. 
- Descortesía directa ${ }^{7}$ (ataque claro y conciso).

- Falsa cortesía (empleo de estrategias de cortesía, imposibilidad de atribuir intención al hablante).

- Descortesía encubierta (ataque implícito, el hablante no se muestra responsable del acto) (Culpeper 2016).

- Acortesía (ausencia de cortesía donde se requiere) (Culpeper 2016).

Además, Culpeper (1996) diferencia entre actos directos y actos indirectos:

1. Los actos directos incluyen técnicas que emplean términos con significados propiamente descorteses, que están convencionalizadas en un contexto específico y con efectos perlocutivos concretos.

2. Los actos indirectos se obtienen por derivación inferencial, mediante el contexto o la forma.

Con esta teoría, pues, se defiende que los actos indirectos pueden incrementar la descortesía, pues se fuerza al oyente a un coste de procesamiento extra.

Seguidamente, Culpeper (2011) determina la descortesía convencional y la divide en tres actos comunicativos, del más semántico al más contextual, por el tipo de inferencia que realiza el oyente:

- Derivados por la forma (según el contenido semántico).

- Derivados por convención (según el contexto, parte del enunciado no está acorde con el resto).

- Derivados por el contexto (mediante inferencia, según el conocimiento compartido).

Culpeper explica que las inferencias derivadas del contexto son posibles gracias a su inserción en determinados contextos, que determina su significado y función: las implicaturas que se obtienen son resultado de la unión del acto verbal y el contexto en el que se realizan, más que al propio acto en sí.

Finalmente, defiende que es posible la cancelación de la implicatura -tanto derivada por convención como derivada por el contexto-, ya que está en relación con lo mutuamente manifiesto (Bell 1997), aunque revela la distancia contextual entre hablantes.

\footnotetext{
${ }^{7}$ Culpeper (1996) también distingue entre descortesía positiva y descortesía negativa, siguiendo el modelo de Brown y Levinson (1987).
} 


\subsection{Entre la Descortesía y la Agresión}

Tradicionalmente la descortesía se ha vinculado a la violencia, y la agresión, al desequilibrio de la armonía social.

Bousfield y Locher (2008) clasifican la descortesía como una subcategoría de la agresión verbal en la que el enunciado es motivado por un sentimiento personal de rencor ("personal sense of spite"), en la que la intención no es expresada de manera clara.

Proponen establecer una escala intencional con la que graduar la intención de atacar que permitiría la distinción y relación entre la agresión verbal, la descortesía y la zona intermedia. Con todo, Bousfield y Locher (2008) aceptan la descortesía como subcategoría de la agresión verbal.

Terkourafi (2008), por su lado, afirma que tanto la cortesía como la descortesía no se realizan de manera directa porque con ellas se evalúa el comportamiento del hablante, y lo que determina si un acto fortalece o amenaza la imagen son sus efectos perlocutivos. Distingue, también, entre grosería implícita (convencional en relación al contexto), grosería explícita (no convencionalmente relacionada con el contexto) y descortesía (no convencionalmente relacionada con el contexto, ataca la imagen, pero no es posible atribuirle la intención al hablante). De este modo, lo que diferencia la descortesía de la grosería es que esta última sí que inherentemente daña la imagen.

Sin embargo, Terkourafi (2008) afirma que, aunque las expresiones queden fijadas convencionalmente y se les atribuya determinado efecto perlocutivo, no siempre producirán ese efecto, sino que dependerá del hablante; todo ello hace menos fija la descortesía.

\subsection{Violencia y Lenguaje}

Vista como fuerza primaria y elemental en el ser humano (Bornhauser 2012), la violencia se entiende como un acto que atenta contra la libertad interior y exterior del individuo (Fuentes Rodríguez y Alcaide Lara 2009). Es un elemento propio de la cultura y de las relaciones sociales [Kolakowski 1999 (citado por Colín Rodea 2011)].

La relación que la violencia mantiene con el lenguaje es destacada: conlleva la ejecución de un acto ilocutivo destinado a dar la imagen del interlocutor (Fuentes Rodríguez y Alcaide Lara 2008). La hostilidad de cualquier tipo de acto de habla 
depende del contexto, del contenido y de la interpretación; es un tipo de comportamiento.

No obstante, si se trata la violencia como descortesía extrema, los actos verbales solo se clasifican como violentos si son explícitos, aunque autores como Brenes Peña (2009a) defienden que la explicitud no garantiza descortesía.

Las teorías tradicionales han considerado los actos descorteses como perlocutivos, pero, si se afirma que la descortesía, así como la violencia, es una estrategia para alcanzar un fin, necesariamente ha de considerarse la intencionalidad del emisor de realizar dicho acto.

Por otro lado, los principios que regulan la descortesía están en evolución constante (Fuentes Rodríguez y Alcaide Lara 2009), y el resultado es la variabilidad de parámetros en la categorización de la descortesía (como el cultural o el personal) (Balandrón Pazos 2004, citado por Brenes Peña 2009a).

Los estudios sobre violencia, descortesía y lenguaje son heterogéneos: según el autor, la agresión se distingue de la violencia, pero no la violencia de la descortesía ni la descortesía de la agresión (Fuentes Rodríguez y Alcaide Lara 2009; Blas Arroyo 2010; Fuentes Rodríguez 2010; Mancera Rueda 2015; Brenes Peña 2009b). En general, no quedan establecidos unos límites claros: se puede tomar en consideración la intención, el fin (Balandrón Pazos 2004) o el grado de lesión (Kaul de Marlangeon 2008), por ejemplo.

\subsection{Redes Sociales}

Por su particularidad, las redes sociales conforman un contexto distinto al de la comunicación oral: el canal, la distancia temporal entre hablantes y la información contextual son distintos (Díaz Pérez 2014).

En Internet y, sobre todo, en las redes sociales encontramos un tipo de comunicación que no puede clasificarse ni de oral ni de escrita; se trata de un híbrido de ambas, -un texto oralizado, en términos de Yus (2010)- que Crystal (2002: 62) denomina Netspeak, "lenguaje escrito que se ha estirado en dirección al habla". Es la gente quien influye de forma creativa en este lenguaje virtual, renegocian los géneros a través de la interacción social (Pano Alamán y Mancera Rueda 2014a; Iglesias Moreno 2012).

Además, la temporalidad, el ritmo, la no respuesta inmediata y el paralenguaje difieren de los de la comunicación cara a cara (Lambert Graham 2008). Aun así, el 
contexto virtual ofrece unas variables de interpretación distintas, pero igual de fructíferas, tales como emoticonos o recursos tipográficos.

El registro más frecuente es el coloquial y, pese a ser tecleado, no se presta la atención ni se realiza la revisión exhaustiva propia del texto escrito. Se trata de un texto escrito "sin filtro", "improvisado", pero que, a su vez, goza de una planificación previa: aparentemente es natural, pero el usuario, antes de emitir -o publicar- el enunciado ha podido leerlo y revisarlo (Mancera Rueda 2015).

\section{¿Descortesía en Internet?}

Las características del mundo virtual crean un contexto en el que la no proximidad personal lleva a la desinhibición y a la liberación de la responsabilidad de la ofensa o el ataque. No es de extrañar que abunde la descortesía, pero no se ha de relacionar con la violencia. El fin es, en gran medida, lúdico y de afiliación (Díaz Pérez 2014), de afianzamiento del vínculo de los receptores, que queda marcado, sobre todo, en el Retuit o el Me gusta.

La temática del momento -derivada, sobre todo, de noticias que causan agitaciónes otro de los factores que encaminan a los usuarios a la descortesía y a la agresión: es común hallarla en temas políticos e ideológicos (Vivas Márquez y Ridao Rodrigo 2015).

Así, parece claro que Facebook y Twitter son espacios favorables tanto para la descortesía -puesto que suponen una libertad expresiva y un mecanismo de desfogue emocional- como para la agresión -ya que se trata de un mundo ficticio y virtual que parece despersonalizar cualquier acción-.

\section{Violencia Linguiística: Propuesta de Clasificación}

Debido a la variedad de criterios considerados en las diferentes clasificaciones de violencia lingüística, hemos creído oportuno establecer una propuesta de clasificación para realizar el análisis (Figura 1).

Los dos extremos que conforman el continuum son la grosería y la agresión. Ambas se consideran actos violentos en diferente grado: la grosería ataca únicamente la imagen del hablante; la agresión, la imagen del hablante y la del oyente. De esta manera, la agresión se concibe como el grado máximo de violencia y la grosería, 


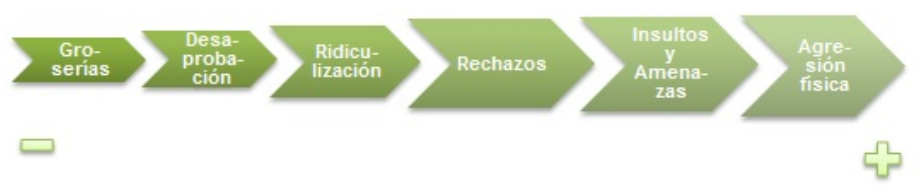

Fig. 1. Continuum de Violencia.

como el mínimo, formando así un continuum con diferentes niveles/grados entre ambos: desaprobación, ridiculización, rechazo y discriminación, insulto y amenaza.

Los parámetros que distinguen grosería y agresión son la variabilidad y la generalidad: la grosería varía entre culturas, contextos e interlocutores -se caracteriza por la subjetividad (Lambert Graham 2008)-, mientras que la agresión es tomada generalmente como tal en cualquier situación y por cualquier hablante (salvo alguna excepción). La grosería supone la transgresión de las normas de conducta culturalmente establecidas y esperadas por los hablantes en cualquier situación. La agresión es la exteriorización de la agresividad como ataque al interlocutor

Ambos extremos son intencionales, el contexto de las redes sociales favorece la percepción intencional (lenguaje escrito y leído simultáneamente), aunque, respecto a la grosería, la permisibilidad de la mala educación varía entre culturas y clases sociales.

Desde una perspectiva lingüística, se tiene en cuenta que los actos violentos, como actos de habla, se pueden realizar de forma explícita o implícita, distinguiendo, así, tres niveles en los que hallar el contenido violento: el contenido violento inferido por la forma, que presenta el mayor grado de explicitud; el contenido inferido por el contexto, que representa un grado intermedio; $\mathrm{y}$, por último, la violencia inferida por convención (véase Culpeper 2011).

Los recursos de las diversas categorías del continuum son varios y, en muchas ocasiones, compartidos en los actos lingüísticos violentos. Su uso es posible gracias al empleo las implicaturas conversacionales, las implicaturas convencionales y el conocimiento compartido, tanto cultural como tecnológico.

Así, en una gradación de lo directo a lo indirecto, estos mecanismos son:

1. Comparaciones

2. Exageraciones

3. Ironías

4. Sarcasmo

5. Interrogaciones y exclamaciones retóricas 


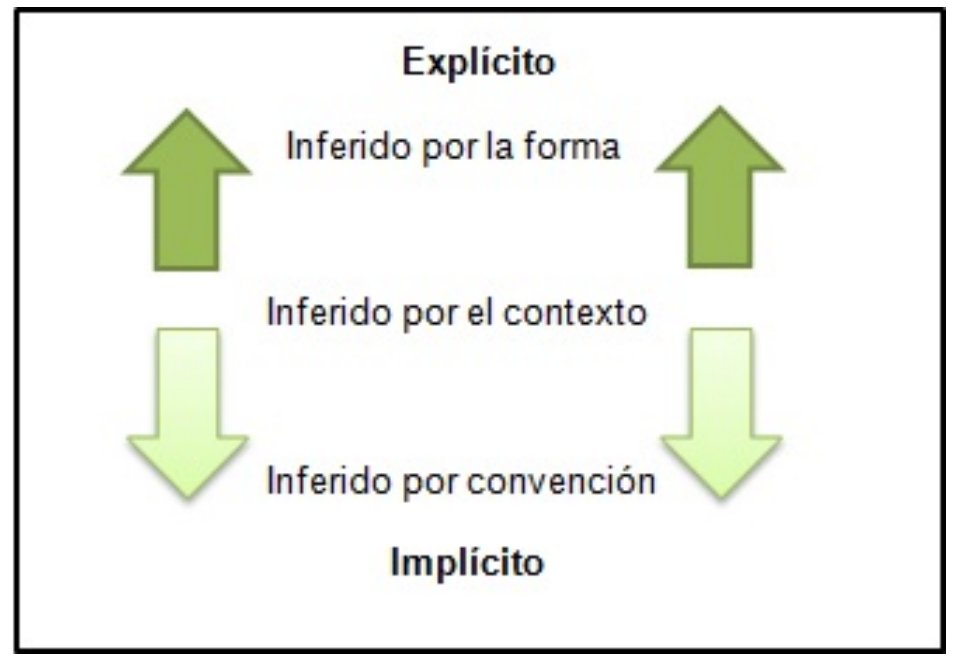

Fig. 2. Gradación Explícito e Implícito.

6. Voces de eco o descripciones.

\section{Categorías del Continuum de Violencia: Análisis}

Teniendo en cuenta la clasificación de violencia lingüística propuesta, hemos realizado un análisis del corpus recopilado.

\subsection{Groserías}

El uso del lenguaje soez y de las palabras malsonantes, pese a ser visto en varias culturas como descortés (Culpeper 2011; Terkourafi 2008), se ha convertido en un hábito lingüístico, una especificidad idiomática de la cultura española como símbolo de libertad de expresión (Rius 2012). Por ello, su empleo ataca a la imagen del emisor, a quien se le atribuye mala educación. Su normalización junto al distanciamiento de internet facilita la interpretación del lenguaje soez como no amenazante para la imagen del oyente.

La grosería se asocia a la defecación, la sexualidad y la digestión, considerándose como "sinónimo de vulgaridad” (Colín Rodea 2011: 12). El Diccionario de 
la Lengua Española (2016) y el Diccionario CLAVE, por su lado, definen grosería como "descortesía, falta grande de atención y respeto" y "rusticidad, ignorancia".

La categoría de groserías incluye, pues, palabras malsonantes (coño, cojones, mierda,...), de las cuales muchas han perdido la correlación con el ámbito escatológico o sexual, fijándose como "tacos":

(1) Todos revueltos en la mierda.

También incluye palabras tabúes u obscenas en determinada cultura $(\text { hostia, puta,... })^{8}$ :

(2) Hay q joderse el amiguismo q sale por cualquier sitio.

Las expresiones relacionadas con el asco son el paso del lenguaje soez a la desaprobación o desacuerdo, porque el efecto de "provocar asco" se relaciona con el ámbito escatológico y digestivo:

(3) Las joyitas de \#microhembrismosson grandes eh, y con joyitas quiero decir ganas de vomitar.

Aunque la grosería sea inherentemente marcada, se puede encontrar, con los recursos tipográficos al alcance, enunciados groseros indirectos en los que el término soez aparece atenuado -mediante juegos fonéticos o el empleo de símbolos tipográficoscomo también enunciados indirectos simples, que se sirven de implicaturas derivadas del contexto:

(4) Eso de que \# LosHomosexualesPeganSIDA es una \# ; \$ \% :)

(5) Mi perro, paseando, me acaba de dar su opinión sobre el \#CaraACaraL6. La he recogido con la bolsa y tirado a la papelera.

Junto a los insultos, el lenguaje soez es una fuente de información sobre las convenciones y normas lingüísticas impuestas por los hablantes (Bernal Linnersand 2007).

${ }^{8}$ En nuestro corpus, los tacos "expresan emociones tales como la ira, la excitación y también actúan como refuerzo" (Rundblom 2013); estos términos muchas veces se complementan con el uso de otras estrategias como refuerzos expresivos. 


\subsection{Desaprobación}

La muestra de discrepancia con otros usuarios conlleva un grado de ataque a la imagen del receptor, pero la distancia entre usuarios y la libertad expresiva de internet atenúan el posible ataque. Aun así, la confrontación de ideas y opiniones fomenta las relaciones sociales y crea lazos positivos (Bravo 1999), y la cultura española [respecto a los suecos, por ejemplo (Fant 1989)] tolera grados elevados de desacuerdo.

En el nivel de lo explícito, esta categoría incluye fórmulas (no apruebo), expresiones del efecto que produce determinado acto en el receptor (me sigue encendiendo) o juicios directos al usuario; se emplean implicaturas conversacionales $\mathrm{y}$, por tanto, se obtiene el contenido mediante la derivación del contexto:

(6) Vergüenza ajena de oír hablar al marido de la \#pedroche \#estoeslahostia solo sabe decir eso

(7) Aparte de que lo veo una irresponsabilidad enorme ... Lo mejor de toso los twits es "soy torero por la gracia de Dios" Dudo mucho que a Dios le guste la manera de torturar toros que tienes

El desacuerdo se puede expresar indirectamente, como se ha comentado, mediante implicaturas contextuales o conversacionales. En éstas se pueden observar expresiones populares, reacciones del usuario frente a la acción y generalizaciones:

(8) Con la que cae y ...\#CompiYogui

(9) Definitivamente, he perdido la esperanza en la humanidad \#LosHomosexualesPeganSIDA

El recurso más empleado en las expresiones de desacuerdo es el de los enunciados de eco (derivados del contexto), interpretaciones de un pensamiento de otra persona que informan de que el emisor tiene en mente lo que tal persona dijo y una determinada actitud hacia ello (Sperber y Wilson 1986):

(10) Gensanta! Escuchar a Rajoy decirle a Sánchez que tiene un problema en los ojos. \#CaraACaraL6

Las ironías se incluyen en los enunciados de eco, aunque la actitud expresada en un enunciado irónico es siempre de rechazo o desaprobación (Sperber y Wilson 1986); no es necesario elementos explícitos que marquen la actitud hacia el pensamiento descrito: 
(11) \#LosHomosexualesPeganSIDA y catarros. Y ojo cuidado con los catarros.

Las comparaciones y las interrogaciones retóricas también son numerosas en nuestro corpus. Las primeras, equiparan la situación con otra con la que comparte el elemento que se desea criticar; en las interrogaciones retóricas se formula una pregunta cuya respuesta sería de negación, mostrando sorpresa y discrepancia:

(12) \#micromachismos "Chicas no dejéis que los novios controlen vuestro teléfono."

Soraya Sáenz de S. María. ¿La responsabilidad de la mujer.?

En la zona de lo implícito, finalmente, se encuentran las descripciones, enunciados que definen el elemento que se critica cuyo desacuerdo se infiere por la perspectiva que toma el emisor en la descripción:

(13) Gente aplaudiendo como una persona agrede por la espalda a otro que no se lo espera. \#PuñetazoARajoy

La discrepancia junto al ataque a la imagen explícito se materializa en la ridiculización.

\subsection{Ridiculizaciones}

La ridiculización supone un grado más que las anteriores categorías en el continuum de violencia lingüística, porque implica de forma evidente un ataque a la imagen -positiva-del oyente; la ofensa es segura.

El ridículo es definido por el Diccionario Salamanca de la lengua española (2006) como "algo que por su rareza o extravagancia mueve o puede mover a risa", marcadamente peyorativo, porque "provoca o puede provocar la burla de los demás".

El uso del humor como herramienta de destrucción de la imagen del interlocutor (Bañón 2010) se ejemplifica en las ridiculizaciones: las burlas, asociadas al humor, atacan de forma clara la imagen -pública sobre todo- del interlocutor.

(14) fran Rivera es tauromaquiavelico

Del mismo modo que en las comparaciones, se asocia a la persona con determinada situación cómica o bien resaltando determinado aspecto de manera burlesca, de modo que denotan cualidad contrarias a las que cabría esperar. En muchos casos, la ridiculización se deriva mediante la inferencia de implicaturas contextuales: 
(15) Es una intelectual del siglo XXII (si si lo he dicho bien) es una avanzada a su tiempo, una obra maestra, a su lado Mozart y Salieri son meros aprendices Una letra cargada de mensaje, e hace reflexionar ¿De dónde venimos? ¿A dónde vamos? ¿Quiénes somos? ¿Si le saco todo el plástico que lleva en el cuerpo me podré hacer un IronMan de juguete a tamaño real?

En varios casos, los elementos de la comparación dependen de la cultura, de modo que la implicatura se infiere por convención (por ejemplo, el término colorear se asocia en la cultura española a la infancia):

(16) Sanchez ya colorea sin salirse del borde. \#CaraACaraL6

Del mismo modo que en las expresiones de desacuerdo, en las ridiculizaciones es común también encontrar interrogaciones retóricas, pero en estos casos funcionan como mecanismo de comparación con situaciones dispares; en estas interrogaciones retóricas la comparación se hace de manera implícita, mediante la ambigüedad léxica o estructural (diera la cara, por ejemplo) o utilizando expresiones que forman parte de la cultura española:

(17) ¿Te gustan los sueldos altos? Pues vas a cobrar \#PuñetazoARajoy

(18) ¿Los toreros no tienen madre que les diga que porque \#FranRiverase tire por un pozo no tienen que tirarse ellos?

Son destacadas las ridiculizaciones que apelan a elementos de actualidad tecnológica, tales como programas de humor, los ordenadores o los propios "memes":

(19) Rajoy error code \#CaraACaraL6

(20) vamos a darles un aplauso y dejamos que se vayan x'Djajajajajaja

(21) Que no han trucado la foto del puñetazo de Rajoy para q parezca peor, que la han editado en insta y han subido el contraste \#punetazoarajoy

Los recursos tipográficos se emplean, sobre todo, como ataque a la ortografía del usuario o para exagerar la pronunciación de forma marcada, en un tono ridículo:

(22) HA ESTADO $* * *$

\footnotetext{
${ }^{9}$ Construcción multimedia que describe situaciones, ideas o pensamientos de forma cómica y burlesca; son características de las redes sociales.
} 
Como muestra del componente cultural de la pronunciación y la entonación, el siguiente ejemplo contiene varias ridiculizaciones con una pronunciación "españolizada" en inglés, que connota ignorancia, o exageradamente inglesa, que connota cursilería o arrogancia:

(23) Con mis zapatos Manolo’s Puedo? Puedo?Porfi!!! Yo también sé decir "Darling osea".

(24) Of coursedear! Lo voy a a apuntar en mi agenda: después de Pilates y del masaje. Qué cool tía!

(25) Al Senado porque yo lo valgo.Rabia, rabiña

(26) Y el Brunch en ese sitio tan divino con esos camareros tan monísimos en Lagasca, OK?

(27) Puedesssss! Churri, osssseaa, quedamos aána para el branxxx? (brunch) porfiiiiii?

(28) Anota en tu aipaz. Y luego me llamas desde tu aifon seis plas. Sí, sí, plas.

(29) Pero el plas es mucho mejor que el plus, no lo dudes! No olvides que estudié en Quembrich!

(30) Yo también tengo un iphone6. Y en cuanto me entero q algún contacto mio no tiene le bloqueo.

Expresiones como "of course", "Darling osea" o "Qué cool tía!" se asocian a personas pijas o de alta clase social; otras como "rabia, rabiña", "jopelines" o "porfiiiii", niñez; y la pronunciación exagerada como "Oxfor" o "aifon seis plas", cursilería y petulancia. Así, estos casos forman parte de las ridiculizaciones implícitas derivadas por convención.

\subsection{Rechazos y Discriminaciones}

El rechazo y desprecio al interlocutor supone un ataque directo a su imagen, tanto positiva como negativa. Se alude a la persona de forma marcada, a pesar de que los mensajes en internet están en realidad destinados a la colectividad (Vivas Márquez y Ridao Rodrigo 2015). Es común encontrar en estos enunciados groserías; el uso del lenguaje soez es empleado como recurso expresivo y, por tanto, aumenta el grado de exhortación:

(31) Y ahora ya que se vayan por el mediterráneo a otro país, a tomar por culo de aqui. 
En la zona de lo implícito, las comparaciones provocan distintos efectos según el elemento con el que se compare al sujeto -como sucede en la desaprobación y en la ridiculización-; en el siguiente ejemplo, se ridiculiza y menosprecia al usuario:

(32) Pilar Rubio, el interés que me produce tu vida personal es igual al interés que muestro por la reproducción del percebe. \#SospechaEH

Las interrogaciones retóricas expresan de forma indirecta el descontento del usuario en relación a determinada acción o al sujeto que la realiza, y el sarcasmo, "burla sangrienta, ironía mordaz y cruel con que se ofende o maltrata a alguien o algo" (como define el Diccionario de la Lengua Española) expresa, mediante un enunciado en eco, el desacuerdo y rechazo, cuyo fin es inherentemente ofensivo, a diferencia de la ironía.

(33) no sabia que los reyes tienen amigos tan rinbonbantes, por dios hasta cuando

(34) por favor no quiteis por asuntos terroristas \#myhyva la juventud iberica que se despierta a la1 para verlo y se vuelve acostar hasta la cena.

Las discriminaciones, las acciones que dan "trato desigual a una persona o colectividad por motivos raciales, religiosos, políticos, de sexo, etc.", como define el Diccionario de la Lengua Española, conllevan un rechazo grupal, que supone un ataque a la imagen positiva y negativa de cada uno de los integrantes del grupo.

En las discriminaciones implícitas derivadas por convención destacan las ovaciones a personajes o acontecimientos históricos que fueron contrarios a las personas -o grupos- que se rechazan o discriminan. Los personajes y hechos históricos a los que se alude, además de ser inherentemente discriminatorios, se asocian a actos físicamente violentos, hecho que incrementa la violencia del enunciado.

(35) Gitanos un trabajo que le quedo pendiente al Canciller aleman.

(36) Robespierrevuelveee!

Los enunciados de eco en las discriminaciones están generalmente asociados a determinados grupos sociales, comunes en enunciados xenófobos y machistas. En muchos de los ejemplos en los que se emplea este recurso se altera el sujeto, de modo que, además de discriminar, se ridiculiza al usuario:

(37) mi jefe me dijo el otro día que me afeitase la barba. A ninguna de mis compañeras le ha pasado. \#micromachismos 
En el caso de la discriminación por sexo, muchos de los enunciados contienen groserías, lo que incrementa el rechazo, denigrando al sexo al que se ataca:

(38) Ojalá darle un pollazo en la frente a cada uno, por la cosa de la \#igualdad. Stop \#micromachismos.

\subsection{Insultos y Amenazas}

Los insultos y las amenazas conllevan un ataque directo a la imagen del interlocutor: los insultos atacan a la imagen positiva; las amenazas, a la imagen negativa. Esta es la principal distinción, pues el grado de violencia es el mismo: cerca del máximo.

Los rasgos que caracterizan a los insultos son la oralidad -traducida por escrito con diacríticos, mayúsculas, puntos suspensivos e interjecciones-, la ambigüedad buscada intencionalmente por el hablante, la inestabilidad y sincronismo, y la gradación, sujeta a las acepciones y estructuras en las que se encuentran (Bernal Linnersand 2007).

Componentes de los insultos que son inherentes a la violencia son la salud (véase Campos Santelices 2010) y los derechos humanos. Se atacan las capacidades humanas del individuo (inteligencia, sexualidad, educación), así como aspectos relativos, rasgos que se consideran positivos (bondad, sinceridad, respeto):

\section{(39) SOIS UNA PUTA ESCORIA \#MYHYV}

(40) eres una troll o eres una auténtica retrasada. No sé porqué, pero me da por lo segundo...

(41) Vale, vale, tomamos nota realeza. Realeza o mentireza!!

Las generalizaciones, mediante implicaturas conversacionales, conllevan un distanciamiento del emisor con el enunciado y el insulto, y las acusaciones conllevan la asociación de una etiqueta o característica que, en la mayoría de casos, es un insulto. Se trata de insultos cuya interpretación se deriva del contexto, en los que la etiqueta no marcada hace que el emisor eluda responsabilidad en el acto.

(42) \#LosHomosexualesPeganSIDA si tirases una piedra en este hastag encontrarías 20 subnormales por $m^{2}$

(43) \#LosHomosexualesPeganSIDA ¿Qué narices? La Iglesia Católica tiene demasiado acceso a Twitter! 
Entre las técnicas que se emplean para insultar, las que ocupan un mayor número de ejemplos en el corpus analizado son la ironía, el sarcasmo y las comparaciones:

(44) Lo reconozco, no me dice nada nuevo este nuevo debate entre Cánovas y Sagasta \#CaraACaraL6

(45) Prefiero ver el bebé en brazos de Fran Rivera toreando, que de tropezón en un gintónic de Rita Barberá

(46) Me encanta el retraso que tenéis. \#LosHomosexualesPeganSIDA

También se utilizan chistes, entre los que pueden incluirse las canciones populares:

(47) Ande andeande País de Pandereta Ande andeande Que no tienen JETAAA \#CaraACaraL6 \#CaraACaraTVE

Los recursos tipográficos (pronunciación exagerada, puntos suspensivos y otros) son un mecanismo de mitigación que "esconden", en lo implícito, el insulto (como se ha visto, también se emplean en el lenguaje soez y las ridiculizaciones):

(48) Pero que se puede esperar de "gente" que ve programas como \#Myhyv?

(49) Espero k mañana no kiten mueres y omvres y bisevelsajolinkon los atentaos ke pesaos los lokos estos \#myhyv

Los insultos más indirectos son los que apelan al conocimiento compartido (derivados por convención), inferidos, así, mediante implicaturas convencionales y culturales:

(50) Lo dicho, hoy Darwin se tendría que tomar un Valium.

(51) Fran Rivera el que lo lea...

La violencia de estos enunciados se percibe solo si se tiene conocimiento de estos aspectos, por tanto, es relativa, mientras que el insulto directo contiene una interpretación peyorativa general (pese a la relatividad cultural).

La percepción de los insultos, con todo, varía en función del contexto; en las redes sociales -en los hashtags y publicaciones de grupos investigados-, debido a la distancia y el desconocimiento de usuarios, el insulto se percibe como un ataque.

Las amenazas se definen como "el anuncio al receptor de nuestra voluntad de llevar a cabo o ejecutar en un tiempo futuro más o menos próximo un acto o acción que 
supone un daño hacia su persona" (Brenes Peña 2009c). Atacan a la imagen negativa del interlocutor, aunque suelen ir acompañadas de ataques a la imagen positiva, de insultos, y apelan a la violencia física de forma explícita:

(52) hijos de puta!!!!!!!! y yo para ganar 8 mil euros tengo ke sufrir mobbing en citroen y luego en la mutua por parte de los psicologos y luego en la inspeccionmedika hijos de puta todos eniaisketemrinar todos colgados en la puerta de $1 \mathrm{sol}$ de una soga y linchamiento publiko e reinita ositayogui!!!!? hijos de putqa ladrones algundiaardereis!!!!!!! y os trituraremos vuesroscrneoskeuaremos de meaderos publikos -un beso compi yogui hay que ser subnormal puta sifilitika de mierda ke no te vea como rajoy por pontevedra o asutriaske vas a chupar igual kerajoy .........

El emisor, en las amenazas indirectas, elude la responsabilidad del acto y puede que no se dirija directamente al sujeto en cuestión:

(53) Si queréis acabar con el bipartidismo, pasadme las coordenadas del plató. \#CaraACaraL6

Dentro de las amenazas, las maldiciones, deseos de sufrimiento y daño hacia el interlocutor son una forma atenuada de amenaza, en la que el interlocutor no se incluye como actante en la acción violenta -en analogía con las acusaciones y los insultos-. Las maldiciones pueden realizarse mediante el uso del subjuntivo (por ejemplo, con la expresión desiderativa ojalá) o bien con el empleo del indicativo (por ejemplo, con la afirmación de que el dolor que se impreca acaecerá):

(54) No es más tonto por q el día no es más largo. Ojalá se reuna pronto con su dios q menudo padre protector esta echo el memo

(55) Eres descpreciable @ Milaximenez te alegra de todo el mal de las personas ya te llegará el turno \#campostelana @ salvameoficial

Las amenazas y los insultos representan un grado elevado de violencia, atacan directamente a la imagen positiva y negativa del destinatario.

\subsection{Agresión}

Tanto la muestra de acuerdo con una acción violenta físicamente como la invitación a que la acción se realice se incluyen en esta categoría, que recoge aquellas expresiones a favor de la agresión física. El ataque a la imagen del interlocutor es evidente. 
Se observan ejemplos que aprueban de forma abierta la acción violenta, pero también es posible realizar dicha aprobación de forma indirecta (por ejemplo, con inferencias por el contexto):

(56) A ver, relajaos ... que ha sido un golpe de nada. Pocos puñetazos recibe el señor ese con todo lo que ha liado! \#punetazoarajoy

(57) 1,5mL de "Hostión 300" a mano abierta, vía facial, tres veces al día; desayuno, comida y cena. En casos extremos (como es el caso), doblar la dosis a $3 \mathrm{~mL}$, dos tomas en desayuno, dos en la comida y dos en la cena. Repetir el tratamiento durante un año

La diferencia de esta categoría con la de amenazas reside en que, en este caso, el emisor no se implica explícitamente en el desarrollo de la acción (con el empleo del subjuntivo, la $3^{a}$ persona del singular o la forma impersonal) y el destinatario, en varios casos, tampoco queda definido individualmente:

(58) Entiendo que uno tuvo error de tipografia ... pero los ultimos 2 de arriba a abajo, izquierda a derecha, habría que golpearlos hasta que les deje de doler...

La apelación a noticias de actualidad, por ejemplo, caracteriza a los ejemplos de agresiones implícitas, de modo que, mediante implicaturas convencionales, culturales o de actualidad, es posible comprender el significado violento:

(59) Pena me da que los seguidores de \#myhyvno vayan en autocar

Finalmente, en esta categoría es posible, también, hallar ejemplos en los que se emplee la tipografía como recurso para expresar pronunciación marcada, escondiendo en lo implícito el acto violento al que se apela:

(60) \#CompiYoguicompi yogui compiyoguicomguiyopicomguillopi con guillopi con guilloti con guilloti na con guillotina

Así las cosas, un acto marcadamente explícito y directo como es la agresión se puede realizar de manera implícita. 


\section{Consideraciones Finales}

\subsection{Resultados}

El objetivo principal de este trabajo ha sido analizar la violencia lingüística y para ello nos hemos servido de un corpus extraído de las redes sociales. Los objetivos que nos planteábamos eran los siguientes:

- Averiguar cómo se establece la relación entre la violencia y el lenguaje.

- Establecer distintos grados de violencia lingüística.

- Determinar qué características poseen los enunciados violentos.

- Analizar las técnicas empleadas en las redes sociales en la emisión de enunciados violentos

- Indicar los tipos de actos violentos que predominan en las redes

La teoría de los actos de habla afirma que hablar es realizar un tipo concreto de acto, de modo que es posible actuar violentamente al hablar. El hecho de que el corpus propio analizado se haya extraído de las redes sociales (plataformas virtuales en las que se interactúa principalmente con palabras) corrobora la existencia del acto de habla violento.

La teoría de la cortesía muestra cómo los actos de habla pueden - de entre otras acciones- eliminar lazos sociales; por tanto, confirma la idea de violencia en el lenguaje que se plasma en la teoría de la descortesía.

Teniendo en cuenta que la bibliografía sobre violencia lingüística no presenta un criterio uniforme para su clasificación, hemos propuesto nuestra propia clasificación de actos violentos. Esta clasificación incluye diferentes tipos de actos violentos según el grado de violencia, considerando el ataque a la imagen del emisor y del interlocutor.

La teoría de la relevancia se ha empleado para sustentar la afirmación de que las categorías de nuestra clasificación pueden realizarse de forma explícita e implícita.

Se aprecia que, salvo en la categoría de groserías, las demás categorías propuestas recurren al significado implícito para transmitir el contenido violento.

- La categoría que presenta mayor contraste entre explícito e implícito es la de ridiculizaciones. Son generalmente comparativas y, en la mayoría de casos, humorísticas (96\%). 


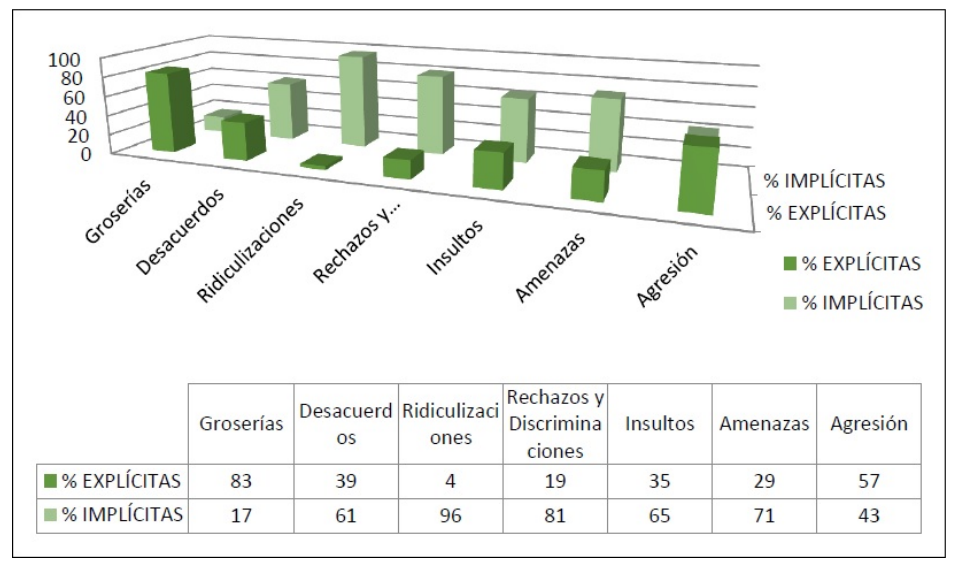

Fig. 3. Categorías de Violencia. Explicitud e Implicitud.

- La segunda categoría con mayor porcentaje de ejemplos implícitos es la de rechazos y discriminaciones (81\%); éstos apelan al conocimiento histórico, como en el caso de la monarquía y el racismo, y al conocimiento del mundo en general, como en el caso del machismo.

- En los insultos, pese a la mayor presencia de formas explícitas respecto a las ridiculizaciones, abundan los enunciados con violencia implícita que se sirven de las implicaturas contextuales; aunque aparezcan insultos marcados como imbécil o gilipollas (35\%), son más comunes los enunciados como Se te ha caído el cerebro (65\%). Lo implícito de los insultos se puede deber a que los casos extraídos pertenecen a grupos (en el caso de Facebook) o bien a hashtags con gran número de tuits; por tanto, la generalización o el uso de implicaturas contextuales distancia al emisor del enunciado, lo que atenúa el insulto directo al interlocutor (en estos casos es desconocido). Las generalizaciones también tienen fuerte presencia en los insultos (15\%), lo que incrementa el número de casos implícitos.

- Los desacuerdos o desaprobaciones no muestran tanto contraste como las otras categorías (39\% explícitos y $61 \%$ de implícitos); sin embargo, aparecen frecuentemente exclamaciones e interrogaciones retóricas.

- En las amenazas también se observa una diferencia sustancial entre casos directos e indirectos (31\% explícitas y $69 \%$ implícitas): los enunciados con violencia implícita expresan el deseo de realizar la acción violenta en un futuro, pero no se explicita, como en la fórmula marcada de amenaza (X va a acción violenta a Y). 
- Las agresiones es la categoría con menor contraste: posee un total de $43 \%$ de casos implícitos. Aunque en gran parte de los casos se trata de enunciados que apoyan acciones violentas, la agresión aparece explicitada en más de la mitad de los enunciados analizados (57\%).

- Las groserías, por último, a causa de su forma generalmente marcada, presenta el caso inverso: mayor número de ejemplos explícitos (83\%).

Brown y Levinson (1987) y Culpeper (1996) presentan en sus teorías diferentes estrategias lingüísticas de cortesía, por un lado, y de descortesía, por otro lado. En la propuesta realizada en este trabajo se han examinado las estrategias de las distintas categorías de violencia lingüística, mediante las cuales se realiza el acto verbal. Tras el análisis del corpus, se observa que los recursos más empleados en las diferentes categorías son dispares, como muestra la Tabla 1.

Cada categoría posee tres recursos, pues se ha tomado la distinción realizada por Culpeper (1996) de gradación de explícito a implícito: inferencia por la forma, inferencia por el contexto e inferencia por convención.

Como muestra la Tabla 1:

- Conforme aumenta el grado de violencia lingüística, aumenta el grado de implícito de los enunciados: las categorías de groserías o desacuerdos y desaprobaciones se sirven de implicaturas contextuales, y las amenazas apelan al conocimiento compartido. El caso de la agresión es particular (es necesario dar indicios para referirse a una agresión física), pero también, en varios enunciados, se alude a noticias de agresiones físicas (por ejemplo, el puñetazo a Rajoy).

- En los insultos, debido a su componente cultural, es lógico que la estrategia de insulto implícito sea la generalización o insultos inferidos por el contexto lingüístico.

- Es particular el caso de las ridiculizaciones, la categoría que presenta mayor caso de números implícitos, cuyo recurso más numeroso es la comparación, con personajes o acciones de actualidad, $\mathrm{y}$, concretamente, el empleo de enunciados de eco.

Teniendo en cuenta que determinados actos de habla amenazan a la imagen y que los actos de habla descorteses tienen la intención de agredir dicha imagen, parece lógico que la violencia lingüística esté presente en estas plataformas. La figura 4 muestra la presencia de las diversas categorías de violencia lingüística en las redes sociales, en general, y en el corpus analizado, en concreto. 


\begin{tabular}{|c|c|c|c|}
\hline Categoría & Explícito & & Implícito \\
\hline & $\begin{array}{l}\text { Inferido por la } \\
\text { forma }\end{array}$ & $\begin{array}{l}\text { Inferido por el } \\
\text { contexto }\end{array}$ & $\begin{array}{l}\text { Inferido por } \\
\text { convención }\end{array}$ \\
\hline Groserías & $\begin{array}{l}\text { Palabras } \\
\text { malsonantes }\end{array}$ & $\begin{array}{l}\text { Referencia al } \\
\text { asco y los } \\
\text { efectos que } \\
\text { provoca }\end{array}$ & $\begin{array}{l}\text { Alusión a } \\
\text { acciones } \\
\text { escatológicas o } \\
\text { sexuales }\end{array}$ \\
\hline $\begin{array}{l}\text { Desacuerdos y } \\
\text { Desaprobaciones }\end{array}$ & $\begin{array}{l}\text { Expresión de } \\
\text { desaprobación }\end{array}$ & $\begin{array}{l}\text { Sensación de } \\
\text { asco y } \\
\text { vergüenza }\end{array}$ & $\begin{array}{l}\text { Interrogaciones } \\
\text { y } \\
\text { exclamaciones }\end{array}$ \\
\hline Ridiculizaciones & Risa & Comparaciones & $\begin{array}{l}\text { Enunciados de } \\
\text { eco, } \\
\text { enunciados } \\
\text { infantiles }\end{array}$ \\
\hline Rechazos & Exhortación & $\begin{array}{l}\text { Oraciones } \\
\text { sarcásticas }\end{array}$ & $\begin{array}{l}\text { Expresión de } \\
\text { hartazgo, } \\
\text { enunciados de } \\
\text { eco }\end{array}$ \\
\hline Insultos & Disfemismos & Generalizaciones & $\begin{array}{l}\text { Acusación de } \\
\text { inconsciencia }\end{array}$ \\
\hline Amenazas & Amenazar & $\begin{array}{l}\text { Explicitación del } \\
\text { deseo de dañar } \\
\text { físicamente al } \\
\text { interlocutor }\end{array}$ & $\begin{array}{l}\text { Referencia a } \\
\text { actos violentos } \\
\text { amenazantes }\end{array}$ \\
\hline Agresión & $\begin{array}{l}\text { Alusión a } \\
\text { agresión física }\end{array}$ & $\begin{array}{l}\text { Implicación no } \\
\text { directa del } \\
\text { emisor en el } \\
\text { acto violento }\end{array}$ & $\begin{array}{l}\text { Exaltación de } \\
\text { agresiones } \\
\text { físicas }\end{array}$ \\
\hline
\end{tabular}

Tabla 1. Categorías de Violencia y Estrategias.

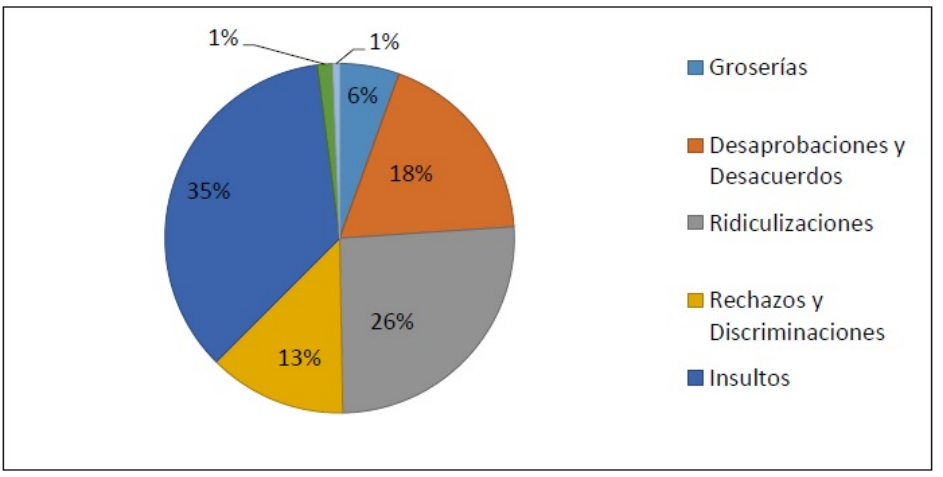

Fig. 4. Categorías de Violencia y su Presencia.

Como se ha explicado, el insulto y la amenaza suponen el mismo grado de ataque, según si se ataca a la imagen positiva o a la negativa. Por ello, se han tomado por separado en el análisis del corpus. 
En vista de los resultados que muestra la figura 4, se puede afirmar que la violencia lingüística está presente en diferentes grados; sin embargo, dicha presencia es desigual. Los resultados del análisis muestran que:

- Las categorías de insultos y ridiculizaciones son las más presentes en el corpus analizado (35\% y 26\%, respectivamente). La afirmación de que, en las redes sociales, los fines que se persiguen con la violencia lingüística son la agresión, por un lado, y el alarde de ingenio, por otro (Díaz Pérez 2014), se confirma.

- Las desaprobaciones o desacuerdos ocupan el tercer lugar (18\%), hecho lógico a causa del uso de estas plataformas virtuales como medio de expresión -teniendo en cuenta las temáticas seleccionadas como fuente del corpus-. Sin embargo, esta libertad de expresión generalizada a veces se confunde con la falta de respeto y educación, que queda demostrada en los rechazos y discriminaciones (13\%). Las características del medio -anonimato, distancia temporal y espacial, escasa información contextual-, por un lado, y las características de las redes sociales plataforma social, imagen, perfil "manipulado", interconexión entre varios usuarios simultáneamente-, por otro lado, favorecen este paso del desacuerdo al rechazo.

- Por último, las amenazas y las groserías, debido, quizá, a su esencial explicitud, tienen presencia escasa en el corpus analizado (1\% y $6 \%$, respectivamente). Cabe mencionar que las groserías, en muchos casos (en un $31 \%$ del corpus), son empleadas como recurso expresivo, por lo que refuerzan la violencia. El caso de la agresión es escaso (1\%), aunque presente, dato de especial interés teniendo en cuenta el no conocimiento entre los usuarios emisores del corpus de ejemplos.

\subsection{Conclusiones}

Tras el análisis y el estudio realizado, las conclusiones a las que llegamos son las siguientes:

La violencia lingüística no es una, sino que comprende varias categorías graduables, pero todas ellas son violentas y, por tanto, atacan al interlocutor. La percepción de que únicamente los grados máximos de violencia (insultos, amenazas y agresión) son violencia propiamente dicha es, como queda demostrado, errónea; son varias las categorías que dañan la imagen del interlocutor, aunque el ataque sea de diferente grado. De hecho, el Código Penal condena el insulto y la amenaza (véase Código Penal, artículos 169, 170 y 171 para las amenazas, y artículo 208, para la injuria), 
la discriminación, y la incitación al odio y la violencia contra grupos o asociaciones por motivos racistas, ideológicos o de enfermedad (artículo 510).

Los recursos que se emplean para hablar violentamente son diversos y, en la mayoría de casos, apelan al conocimiento histórico, cultural y tecnológico. Cada categoría se materializa tanto explícita (inferido por la forma) como implícitamente (inferido por el contexto o por convención). En la mayoría de casos, la violencia lingüística pasa por materializarse de forma implícita. Sin embargo, si la prueba no es explícita, es decir, si el acto no es directo, no se considera delito. Teniendo en cuenta que es mucha más la violencia implícita que la explícita, cabría replantearse el considerar solamente los casos explícitos como actos de violencia, así como la necesidad de presentar pruebas explícitas para poder denunciar (en el caso del maltrato psicológico, por ejemplo).

En relación a las redes sociales, estas suponen un nuevo modo de comunicación, como también de relaciones sociales (poseen diferencias con las presenciales); por ende, se observa un nuevo contexto en el que aparece la violencia lingüística. Se observa una gran presencia de ataque a través de insultos y amenazas, de humor por medio de ridiculizaciones y de crítica mediante desacuerdo y desaprobaciones. Teniendo en cuenta que la comunicación virtual es en gran parte lingüística y, particularmente, "escrita", queda demostrado el importante peso de la violencia lingüística, poco considerada socialmente respecto a la violencia física.

Al tratarse de plataformas sociales, en las que cada usuario posee una imagen "virtual", se propicia el alarde de ingenio y, por tanto, los enunciados implícitos. Las ridiculizaciones, categoría "intermedia" en la clasificación propuesta, suponen una burla en presencia de miles de usuarios, lo que propicia el ciberacoso, pues, además, el testimonio escrito de la ridiculización "alarga" el ataque. También es necesario un planteamiento estricto que limite tanto las libertades de expresión como el respeto a los usuarios, sobre todo teniendo en cuenta el auge de las redes sociales entre los adolescentes.

De especial interés es el hecho de que, pese al anonimato y la distancia social que presenta el mundo virtual, la violencia lingüística es en la mayor parte de los casos implícita; si en las relaciones virtuales, con mayor distancia y desconocimiento entre interlocutores, tiene más presencia la violencia lingüística en su vertiente implícita, es lógico que en las relaciones sociales cara a cara, dicha presencia sea todavía mayor. Todo ello lleva a reafirmar la necesidad de reflexionar sobre la explicitud requerida para considerar los casos de violencia como tales.

En síntesis, el estudio y el análisis realizado demuestran que la violencia lingüística tiene el mismo peso que la violencia física; se sirve de otra forma de materialización, 
pero la acción es la misma: violencia. En muchos casos es implícita y puede no ser percibida claramente, lo que favorece su incremento, y las redes sociales suponen un nuevo contexto en el que la violencia está presente y, en concreto, la lingüística. Queda demostrada la necesidad de cuestionar y observar los "vacíos legales" de estas nuevas formas de relaciones sociales.

\section{References}

1. Albelda Marco, M. \& Barros García, M.J. (2013). La cortesía en la comunicación. Madrid: Arco Libros.

2. Androutsoupoulos, J. \& Beisswenger, M. (2008). Introduction. Data and Methods in Computer-Mediated Discourse Analysis.Language@Internet, 5(9): 1-7.

3. Bañón Hernández, A.M. (2010). Comunicación destructiva y agresividad verbal en la Red. Notas en torno al discurso sobre las enfermedades raras. Discurso \& Sociedad, 4(4): 649-673.

4. Bell, A. (1984). Language style as audience design. Language in Society, 13: 145-204.

5. Bernal Linnersand, M. (2007). Categorización sociopragmática de la cortesía y de la descortesía: Un estudio de la conversación coloquial española. Estocolmo: Stockholm University.

6. Blas Arroyo, J.L. (2008). La descortesía verbal en contextos institucionales: entre la realidad y el espectáculo. In Fuentes Rodríguez, C. \& Alcaide Lara, E.R. (eds.), Manifestaciones textuales de la descortesía y agresividad verbal en diversos ámbitos comunicativos (pp. 78-97). Sevilla: Universidad Internacional de Andalucía.

7. Blas Arroyo, J.L. (2010). La descortesía en contextos de telerrealidad mediática. Análisis de un corpus español. In Orletti, F. \& Mariottini, L. (eds.), (Des)cortesía en español. Espacios teóricos y metodológicos para su estudio (pp. 183-208). Roma-Estocolmo: Università degli Studi Roma Tre-EDICE.

8. Bornhauser, N. (2012). Consideraciones en torno a la violencia. "Más allá" de las palabras. Atenea, 5062: 137-152.

9. Bousfield, D. \& Locher, M.A. (2008). Impoliteness in language: studies on its interplay with power in theory and practice. Alemania: Deutsche Nationalbibiliothek.

10. Bravo, D. (1999). ¿Imagen "positiva" vs. Imagen "negativa"? Pragmática sociocultural y componentes de face. Oralia, 2: 155-184.

11. Bravo, D. (2008). Situación de habla, recursos comunicativos y factores lingüísticos en la interpretación de objetivos de cortesía. In Briz, A., Hidalgo, A., Albelda, M., Contreras, J. \& Hernández, N. (eds.), Cortesía y conversación: de lo escrito a lo oral. III Coloquio internacional programa EDICE (pp. 12-24). Valencia: Universitat de València.

12. Brenes Peña, M.E. (2007). Estrategias descorteses y agresivas en la figura del tertuliano televisivo: ¿trasgresión o norma? Lingüística en la red: 1-19 
13. Brenes Peña, M.E. (2009a). La agresividad como espectáculo en la televisión de hoy. La entrevista televisiva. In Fuentes Rodríguez, C. \& Alcaide Lara, E.R. (eds.), Manifestaciones textuales de la descortesía y agresividad verbal en diversos ámbitos comunicativos (pp. 141-160). Sevilla: Universidad Internacional de Andalucía.

14. Brenes Peña, M.E. (2009b). La agresividad verbal y sus mecanismos de expresión en el español actual. Universidad de Sevilla, Sevilla.

15. Brenes Peña, M.E. (2009c). La expresión de la amenaza en el lenguaje juvenil. Cultura, lenguaje y representación, 7: 39-58.

16. Campos Santelices, A. (2010). Violencia social. Costa Rica: Editorial Universidad Estatal a Distancia.

17. Carrasco Santana, A. (1999). Revisión y evaluación del modelo de cortesía de Brown \& Levinson. Pragmalingüística, 7: 1-44.

18. Cepeda, G. (2007). Discurso y (des)cortesía. Discurso \& Sociedad, 1(2): 248-269.

19. Ciber Sociedad (2009). IV Congreso de la Ciber Sociedad 2009, Crisis analógica, futuro digital. Redes sociales y medios de comunicación.

20. Colín Rodea, M. (2011). Selecciones lingüísticas y discursivas en la "visibilización" de la dimensión moral de la violencia: el insulto moral. Discurso \& Sociedad, 5 (3): 422-468.

21. Crystal, D. (2002). El lenguaje e Internet. Madrid: Cambridge UniversityPress.

22. Culpeper, J. (1996). Toward an Anatomy of Impoliteness. Journal of Pragmatics, 25 : 349-67.

23. Culpeper, J. (2011). Impoliteness: using language to cause offence. Cambridge: Lancaster University.

24. Culpeper, J. (2016). Impoliteness strategies. In Capone, A. \& Mey, J.L (eds.), Interdisciplinary Studies in Pragmatics, Culture and Society.Perspectives. Pragmatics, Philosophy \& Psychology, 4: 421-445.

25. Díaz Pérez, J.C. (2014). Creatividad léxica y descortesía en los medios de comunicación virtual. Revista de Filología, 32: 81-98.

26. Escandell Vidal, V. (1993). Introducción a la Pragmática. Barcelona: Ariel.

27. Fant, L. (1989). Cultural mismatch in conversation: Spanish and Scandinavian communicative behaviour in negotiation settings. Hermes Journal of Linguistics, 3: 251-260.

28. Fuentes, C. (2010). Violencia y discurso. Discurso \& Sociedad, 4(4): 643-648.

29. Fuentes Rodríguez, C. \& Alcaide Lara, E.R. (2008). (Des)cortesía, agresividad y violencia verbal en la sociedad actual. Sevilla: Universidad Internacional de Andalucía.

30. Fuentes Rodríguez, C. \& Alcaide Lara, E.R. (2009). Manifestaciones textuales de la descortesía y agresividad verbal en diversos ámbitos comunicativos. Sevilla: Universidad Internacional de Andalucía.

31. Garrido Rodríguez, C. (2006). Procedimientos para la cortesía en la conversación. Cultura, lenguaje y representación, 3: 57-71.

32. Goffman, E. (1967). Interaction Ritual: Essays on Face-to-Face Behaviour. Nueva York: Doubleday Anchor Books.

33. Gómez Arraigada, H. F. (2013). Desinformación en Internet y hegemonía en redes sociales. Revista GPT Gestión de las Personas y Tecnología, 16: 28-34. 
34. Grice, H.P. (1975). Logic and Conversation. In Davis, S. (ed.) (1991), Pragmatics. A Reader (pp. 305-315). New York: Oxford University Press.

35. Haverkate, H. (1994). La Cortesía Verbal. Madrid: Gredos.

36. Haverkate, H. (2012). Cortesía y veracidad. Lingüística y Literatura, 62: 19-27.

37. Iglesias Moreno, P.A. (2012). El lenguaje de las Redes Sociales. In De Haro, M.V., Gandío, M.M. \& Hernández, M. (coords.), Historias en red. Impacto de las redes sociales en los procesos de comunicación. Murcia: Ediciones de la Universidad de Murcia.

38. Kaul de Marlangeon, S. (2008). Tipología del comportamiento verbal descortés en español. In Briz, A.M., Hidalgo, A., Albelda, M.; Contreras, J. \& Hernández, N., Cortesía y conversación: de lo escrito a lo oral. III Coloquio internacional programa EDICE (pp. 254-266). Valencia: Universitat de València.

39. Kaul de Marlangeon, S. (2012). Encuadre de aspectos teórico-metodológicos de la descortesía verbal en español. In Escamilla Morales, J. \& Henry Vega, G. (eds.), Miradas multidisciplinares a los fenómenos de cortesía y descortesía en el mundo hispánico (pp. 76-107). Barranquilla-Estocolmo: Programa EDICE.

40. Kolakowski, L. (1999). De la violencia. Discurso \& Sociedad, 5(3): 422-468.

41. Lambert Graham, S. (2008). A manual for (im)politeness?: The impact of the FAQ in an electronic community of practice. In Bousfield, D. \& Locher, M.A (eds.), Impoliteness in language: studies on its interplay with power in theory and practice (pp. 281-304). Alemania: Deutsche Nationalbibiliothek.

42. Mancera Rueda, A. (2015). Los estudios sobre (des)cortesía y actividades de imagen en las redes sociales: notas para un estado de la cuestión. Textos en Proceso, 1(1): 50-70.

43. Medina López, J. (2011). Modelos de (des)cortesía verbal en la prensa española, el caso de "El Día" (Tenerife). RILCE. Revista de Filología Hispánica, 29(2): 365-388.

44. Ministerio de Justicia (2016). Código penal y legislación complementaria. Edición actualizada a 21 de enero de 2016, Boletín Oficial del Estado, Agencia Estatal Boletín Oficial del Estado, Madrid.

45. Pano Alamán, A. \& Mancera Rueda, A. (2014a). Identidades falsas en Twitter: la ironía y el humor verbal como mecanismos paródicos. Discurso y sociedad, 8(3): 507-536.

46. Pano Alamán, A. \& Mancera Rueda, A. (2014b). Las redes sociales como corpus de estudio para el Análisis del discurso mediado por ordenador. Humanidades digitales: desafios, logros y perspectivas de futuro, Anexo 1: 305-315

47. Pano Alamán, A. \& Moya Muñoz, P. (2016). Una aproximación a los estudios sobre el discurso mediado por ordenador en lengua española. Tonos Digital, Revista Electrónica de Estudios Filológicos, 30.

48. Portolés, J. (2004). Pragmática para hispanistas. Madrid: Síntesis.

49. Rius, M. ¿Somos malhablados?, La Vanguardia, Vida. Recuperado el 20/01/2012 de http://www.lavanguardia.com/estilos-de-vida/20120120/54244529265/somosmalhablados.html

50. Ruiz Antón, L.F. (1998). La acción como elemento del delito y la teoría de los actos de habla: cometer delitos con palabras. Madrid: Universidad Complutense de Madrid.

51. Searle, J. (1976). Actos de habla indirectos. Una taxonomía de los Actos Ilocucionarios. Teorema, 6(1): 43-77. 
52. Searle, J. (1986). Actos de habla. Madrid: Cátedra.

53. Sperber, D. \& Wilson, D. (1986). La Relevancia. Comunicación y procesos cognitivos. Madrid: Visor.

54. Terkourafi, M. (2008).Toward a unified theory of politeness, impoliteness, and rudeness. In Bousfield, D. \& Locher, M.A. (eds.), Impoliteness in language: studies on its interplay with power in theory and practice (pp. 45-76). Alemania: Deutsche Nationalbibiliothek.

55. Vivas Márquez, J. \& Ridao Rodrigo, S. (2015). "Lo siento pero me parecen horribles!!!” Análisis pragmalinguiístico de la descortesía en la red social Facebook. Revista de Filología, 33: 217-236.

56. Yus, F. (1997). Cooperación y relevancia. Dos aproximaciones pragmáticas a la interpretación. Alicante: Publicaciones de la Universidad de Alicante.

57. Yus, F. (2010). Ciberpragmática 2.0. Barcelona: Ariel.

\section{Author's Biodata}

Susana Campillo Muñoz es graduada en Lengua y Literatura Hispánicas por la Universitat Rovira i Virgili (Tarragona). 